\title{
Towards the Development of Regional Risk Profiles and Adaptation Measures for Sea Level Rise
}

\author{
Bilal M. Ayyub, PhD, PE \\ Professor and Director, Center for Technology and Systems Management, \\ Department of Civil and Environmental Engineering, University of Maryland College Park, MD 20742, USA \\ 301-405-1956(Tel),ba@umd.edu \\ Michael Kearney, PhD \\ Professor, Department of Geography, \\ University of Maryland College Park, MD 20742, USA \\ kearneym@geog.umd.edu
}

\begin{abstract}
Risks from future sea level rise entail significant uncertainties concerning overall potential impacts, the specific threats faced by particular areas and what benefit or costs are associated with strategies for addressing such risks. The proposed risk quantification and management framework is consistent with quantitative risk analysis practices in order to enable decision making in a multi-hazard framework. Quantifying risk enables the examination of adaptation measures requiring basic physical inputs that can underpin viable engineering solutions for sustaining coastal infrastructure.
\end{abstract}

Keywords: Coastal engineering, Coastal infrastructure, Climate change, Extreme event, Risk, Sea level rise.

\section{Background}

By the end of this century, some estimates suggest at least 100 million people worldwide will be affected by rising sea levels. This number, large as it may be, hinges on the relatively conservative upper end of scenarios for future sea level rise of the Fourth Assessment of the Intergovernmental Panel on Climate Changes (IPCC 2007). Among many climate scientists there exists considerable disquiet that this top end estimate could prove too low, as the contribution from polar ice melting still remains highly uncertain. The resulting impacts on global sea levels could be a rise on the order of 19.6 feet. An increase in the global trend is likely, and this increase will be of the order of two to two-anda-half times what occurred in the 20th century, historically a period of the highest rate of sea level rise in the last thousand years (Kearney 2008).
The 2008 Hurricane Ike, a Category 5 storm, hit the east Texas coast in one of the most populated and commercially important metropolitan areas in the Gulf of Mexico, Galveston Bay and Galveston of the Houston metropolitan region. Among the many concerns about the hazards the storm posed to people and structures, was the fate of Galveston Island and the city of Galveston. The catastrophe of the 1900 hurricane still resonates to this day in the area. As it turned out, like had happened many times since the seawall had been constructed in 1903, damage to Galveston was largely confined to wind and flood damage; the horrendous destruction wrought by huge storm waves in the 1900 hurricane was largely avoided, with only fairly local damage by wave overtopping of the sea wall. It is difficult to imagine that engineers who designed the Galveston sea wall in 1903 had any idea that it would still be serving its purpose more than a century later, even though the limited wave overtopping during Ike 
suggests that the freeboard of the structure is no longer sufficient. The state of coastal science and engineering back then, regarding wave generation and dynamics, the loads that waves could impose on coastal structures, and the relations of shore processes to sea level rise, even they realized sea levels were rising, was primitive. The march of coastal science and engineering since has been impressive. Nevertheless, in application there still much left to be done, particularly when tied to maintaining present and future infrastructure in an era where sea levels could rise faster than at any time since the advent of instrumental records; hence, no detailed analogues. Even knowing where the future shoreline might be in many cases, in lieu of simple submergence, remains problematical.

The challenge of such a sea level rise is indeed formidable, and requires immediate attention in order to examine associated risks and to assess the socioeconomic impacts for the purpose of developing appropriate long-term measures and mitigation strategies. The impacts on other parts of the globe such as southern Asia can be total devastation for particular countries.

One of the important economic consequences of sea level rise that merits immediate attention is the impact on ports, shipyards, naval installations, and the transportation arteries that support them. As an example, in the Chesapeake Bay the Port of Baltimore has experienced in recent years a $28 \%$ growth in foreign cargo, amounting to 32 million tons in 2004. The Port is directly responsible for 19,000 direct jobs (\$2.4 billion in personal wages and salary), $\$ 2$ billion in business revenue, and generates $\$ 278$ million in state, county and municipal taxes (State of Maryland Governor's Office 2006). The total economic impact is well beyond these estimates. Comparable figures are available for the Port of Norfolk and Portsmouth in Virginia, plus with the nation's largest naval installation, the added impact on national security and the ability to project national power to areas across the world.

\section{Sea-Level Rise and Associated Risks}

Fairbridge $(1950,1958,1960,1961)$ documented that the ocean levels rose and fell over long time scales producing what has become known as the Fairbridge Curve of the Holocene Eustatic Fluctuations based on detailed observations off Western Australia and afterwards from elsewhere in the world. He formulated the hypothesis that sea levels had been rising for the last 16,000 years and that the rise showed regular periodic oscillations of rise and fall over this period with oscillations continued throughout the last 6,000 years to the present time, but with diminishing amplitude. The oscillations include a relatively short periodicity component of relatively rapid rises and falls of up to four meters, although up to three meters is more common, taking place over periods of no more than 10 or 20 years. This short-periodicity component would now have catastrophic consequences for the world. Over the next 100 years and possibly within our lifetime such an occurrence is likely. The periodicities are revealed in a rich variety of sources, including: geology; geomorphology; glaciations; sediments; sand dunes; beach rock; the circulation of the ocean; geomagnetic records; and the records of the isotopes of carbon, oxygen, beryllium, chlorine and hydrogen in tree rings, ice cores, biota, rocks, air and water (Mackey 2007; Finkl 1995 and 2005).

Changes in the average sea level involve several primary categories of variables that are interdependent with nonlinear associations: (1) steric (volume) due to changes in temperature (thermosteric) and salinity (halosteric) levels of oceans; (2) worldwide carbon inventory; (3) the shape of the basins that contain the oceans; (4) the mass of water in these basins from melting of glaciers; and (5) local variations in land adjacent to the ocean basins. Global warming causes the oceans to warm up; this in turn causes thermal expansion of the oceans leading to rising sea level. Global warming also causes the poles to warm up leading to the melting of land-based ice sheets, glaciers, and ice caps. For example, most of the eastern and western United States coastlines are observing a steady rise. The Gulf Coast is observing a more concerning steady sea-level rise rate; whereas some locations in Alaska are actually observing a fall in sea level. This fall is due to uplifting of land due to tectonic plates, i.e., the uplifting rate is greater than the sea level rise rate, making it appear as if sea levels were dropping when in fact land is moving more rapidly upwards. In addition to volumetric expansion of oceans and melting of ice sheets, ocean salinity can cause oceans to expand or contract, changing sea level both locally and globally. In 
simple terms, ocean salinity is primarily caused by the amount of carbon present in water. Human beings are redistributing carbon around the globe. Oceans absorb this "carbon" and become more saline, increasing their capacity to store heat and therefore expanding further. Carbon concentrations are greatest in the North Atlantic Ocean where industrialized nations are located (CCSP 2009; Dean 1987; IPCC 2007). These variables can form a basis for defining scenarios as recommended by the IPCC (2007) with associated probabilities.

Defining risk as the potential of losses for a system resulting from an uncertain exposure to a hazard or as a result of an uncertain event (Ayyub 2003) offers a basis for risk quantification for identified risk events or event scenarios and associated rates, system vulnerabilities and potential consequences. This definition offers a basis to quantify risk as the rate (measured in events per unit time, such as a year) or probability that lives, economic, environmental, and social/cultural losses will occur due to an event including the non-performance of an engineered system or component. The nonperformance of the system or component can be quantified as the probability that specific loads (or demands) exceed respective strengths (or capacities) causing the system or component to fail, and losses are defined as the adverse impacts of that failure if it occurs. Risk can be viewed to be a multi-dimensional quantity that includes event-occurrence rate (or probability), event-occurrence consequences, consequence significance, and the population at risk; however, it is commonly measured as a pair of the rate (or probability) of occurrence of an event, and the outcomes or consequences associated with the event's occurrence that account for system weakness, i.e., vulnerabilities. Another common representation of risk is in the form of an exceedance rate (or exceedance probability) function of consequences. In a simplified notional (or Cartesian) product, it is commonly expressed as:

Risk $=$ Event rate $\times$ Vulnerability $\times$ Consequence

This equation not only defines risk but also offers strategies to control or manage risk: by making the system more reliable through vulnerability reduction or by reducing the potential losses resulting from a failure or impacting event rates. The probability of failure part of the equation can be influenced by engineers by strengthening of existing structures or by adding additional protection; however the consequence part is highly dependent upon the actions and decisions made by residents, government and local officials, including land-use changes, protection measures of coastal areas, response and population relocation plans and practices. Event rates can be impacted by policies relating to global warming and carbon reduction as examples. In densely populated areas, simply increasing the reliability of a protection system may not reduce risks to acceptable levels and increasing consequences through continued development of flooding-prone areas can offset any risk reductions.

\section{Primary Physical Processes and Considerations}

\subsection{Shore Erosion and Retreat}

There is no more fundamental and crucial information in assessing risk and sustainability of developed coasts from sea level rise than to be able to forecast the position of shoreline. Flooding and wave damage from storms, risks to life and limb, and even assurance that structures or development constructed today will meet their designed amortization schedules, all either increase (in the case of the first two) or decrease (in the case of the last) with proximity to the shoreline. For the last thirty years, immense effort has been devoted to deriving estimates of shore erosion or retreat rates. Because obtaining rates from in situ shore profiles is time consuming and likely to be flawed by being too short in record and site specific, historical maps and aerial photography have been the principal means of obtaining long term and synoptic erosion and/or retreat rates. This has been both good and bad. Good, because the data are probably reliable up to the date compiled (and probably for the immediate future); however, bad because there is no way beyond linear extrapolation to forecast future trends from such information. Evidence supports that the late 20th sea level record documents considerable, even increasing, inter-decadal variability. The 1990s and early 2000s are best the example of this, with an acceleration (in the U.S. middle Atlantic Coast, exceeding $>1 \mathrm{~cm} / \mathrm{yr}$ ) that was the largest of the last half century, followed by a deceleration with dramatic intraannual low stands in sea level. If even a reasonable correlation between sea level rise and shore erosion/retreat could be determined by regression - and 
then probably only on sandy beaches as discussed below - it would be credulous to believe that such a relationship might be meaningfully extrapolated for predicting future trends decades away.

Bruun (1962) sometime ago proposed a now a wellpracticed relationship between the amount of sea level erosion and sea level rise. This two dimensional model indicates that the $\mathrm{R}$, the amount of shoreline retreat is a function of the rise in sea level, $\mathrm{S}$, the cross-shore width of the active profile, L, the depth of closure, h, and B, the elevation of the dune crest or cliff, i.e., the landward limit of sediment transport. In simple algebraic form, the model is as follows:

$$
R=\frac{S L}{h+B}
$$

The chief difficulty in applying this model is determining the depth of closure, or the depth of the seaward of the active beach profile.

A principal recurring theoretical objection to Bruun's rule is that it is predicated on an equilibrated beach profile. Bruun original postulate for the existence of equilibrium profile was based on analyses of beach profiles in Monterey, California, and Denmark (Bruun 1954). Bruun found that a power function provided the best mathematical description of profile plan as follows:

$$
h(y)=A y^{2 / 3}
$$

where $y$ is the distance in meters in the shore normal direction, $h$ is the depth in meters, and $A$ is a profile scaling factor related to sediment size (Dean 2002). Bruun assumed that the profile was in equilibrium, an assumption later validated by Dean (1977). In the decades since Dean's validation, there have been variations offered to improve Bruun's original model for specific conditions, particularly for gravity forcing in the upper profile (Komar 1998), but the basic power relationship holds. Only in the instance of severe coastal storms tracking close to shore, which can produce high, short period waves of great erosive power, moving sediment so far offshore that it may take decades for the summer long period swell to return it (Zhang et al. 2004), is the assumption of an equilibrium profile tacitly inviolate, and thus excluding a necessary theoretical underpinning of the model. To be sure, it also is open to question whether the Bruun rule would still apply if global sea level rise was to accelerate toward the top of the envelope of the IPCC's estimates. With such a rapid rise, far beyond the global sea level trends current when Bruun and others made their observations, the likelihood of an equilibrium existing in beach profiles may be moot, if for no more fundamental reason than shoreline retreat would shift largely to coastal submergence rather erosion.

In summary, then, usefulness of the Bruun rule lies not so much in ability to predict shoreline retreat during a period of perturbation, i.e., during sea level rise, but rather as a scenario-building tool for predicting how in relaxation beaches adopt a new equilibrium profile, during which the shoreline assumes a new landward position. It is limited to sandy beaches - not mud beaches, marsh shorelines, and the like - comprising geometrically simple coasts. Bruun never argued for universality of his model. Recent work (Zhang et al. 2004), refining the multiplier effect of the shoreline retreat vis-à-vis sea level rise of the Brunn Rule for U.S. Atlantic Coast barrier beaches, can provide a reasonable forecast of where shorelines might be with a certain rise in sea level.

For non-sandy beaches and shorelines, especially along irregular coasts, the modeling of future shoreline position with sea level rise currently lacks any physical foundation. Rosen (1980) tried to adapt the Bruun rule for Chesapeake Bay as an example, an estuarine system of over $9,600 \mathrm{~km}$ of shoreline, and predictably had very limited success. Apart from the fact that are few sandy beaches in the Chesapeake, with mud or marsh shorelines predominating, the absence of ocean swell waves means that the efficiency of the comparatively small storm waves is heightened since sediment eroded during winter stays offshore unlike the open coast where long period swell out of the southeast moves much of it back on shore in summer.

\subsection{Waves: The Force of Coastal Change}

Rising sea levels will not only erode shorelines and cause coastal submergence, exposing infrastructure to inundation, but also bring the power of waves closer to structures not previously within the zone of potential wave attack, but impose greater static and dynamic loads on existing marine facilities. Long shore transport 
rates also are a function of incident waves and their height.

The actual influence of sea level rise on wave dynamics as they might affect coasts may be most pronounced in protected shallow coasts like bays and estuaries. If one assumes that open coast shore profiles will equilibrate as sea levels rise, then the near-shore depth parameter should effectively remain unchanged. Open coasts will not be immune from the general effects of global change, however; already there is evidence that significant wave heights $\left(H_{s}\right)$ from intense coastal storms are increasing in both the North Pacific and North Atlantic (Ruggiero et al. 2010). Nevertheless, because the mud or marsh shores of estuarine coasts probably do not maintain a nominal equilibrium profile, at least in the sense as documented by Bruun and others, then a deeper shore profile in a shallow bay could lead to potentially larger waves from the same wind field. In Chesapeake Bay, with an average depth of $4.5-6.1 \mathrm{~m}$ $(15-20 \mathrm{ft})$, a rise in sea level rise by $2100 \mathrm{AD}$ at the upper envelope of the IPCC AR4 predictions $(\sim 60 \mathrm{~cm})$ would be a proportionately significant increase in water depth $(\sim 13 \%)$, with the potential for proportionately much larger waves.

Because wave power varies by the square of the wave height, the implications of deeper water in shallow protected coasts becomes clear. As an example, consider the equation for maximum drag force $\left(F_{D}\right)$ exerted by waves on cylindrical object like a piling:

$$
F_{D}=1 / 2 \rho C_{D} H^{2} K
$$

where the principal parameters are: $C$, the diameter of the cylinder; $C_{D}$, the coefficient for the wave drag exerted on it; $H$, the wave height; and $K$, a coefficient. This formula is predicated for shallow water situations using solitary wave theory, and does not assume oscillatory conditions of Airy wave theory (Goda 2007).

For vertical structures like sea walls, bulkheads, or breakwaters, accurate wave height predictions not only are necessary for estimating hydrodynamic loads but also designing freeboard limits with acceptably low probabilities of wave exceedance - e.g., 0.001 for a critical facility or buildings with high occupancy rates. Moreover, the breaking wave force $\left(F_{b}\right)$ exerted against vertical structure is again related to the square of the stillwater depth $(d)$ :

$$
F_{b}=1.1 C_{p} \gamma d^{2}+1.91 d^{2}
$$

where the other parameters are: $C_{p}$, the dynamic pressure coefficient; and $\gamma$, the specific gravity of water.

Even wave runup, an important consideration in the design of inclined sea walls, is a function of the significant wave height $\left(H_{s}\right)$. The relationship is also dependent on wave incidence, the surf-similarity parameter $(\xi)$, slope angle, and material permeability. However, because runup is critical to the determination of sea wall overtopping and the vulnerability of landward structures to flooding and even wave damage, again the influence of sea level on significant wave height cannot be discounted.

\subsection{Sea Level Rise and the Tidal Frame}

The literature on the effects of global warming and accelerated rates of sea level rise is replete with descriptions of increased flooding risk and loss of life, damage to coastal structures, and overall for potential social disruption. The threat of even more powerful waves is also considerable; however, often missing in such hazard forecasts is any mention of tides, other their capacity to facilitate the damage done by storm surge and waves to communities if storms hit the coast at high tide, especially a perigean spring tide. This is not wholly surprising as tides, for many coasts, except those at the upper end of the mesotidal range or higher, are often secondary to waves in coastal evolution. For example, in a microtidal coast like Chesapeake Bay where mean tidal range is in the middle and upper part of the estuary is $0.3 \mathrm{~m}$ or less, tidal velocities are low. In Baltimore Harbor as an example, mean tidal velocities average about $0.8 \mathrm{kts}\left(\sim 1.5 \mathrm{~km} \mathrm{hr}^{-1}\right)$ according to NOAA (1999). Such low velocities have very little erosive potential, especially for the estuarine mud that characterize much of the Bay as Shields Function makes clear; but this could change if the tidal frame is increased as a result of sea level rise.

Definitive studies of tidal amplification with rising sea levels are few, and where they have been investigated it is not clear whether human activities (e.g., port construction changing harbor hydrography) contemporary with sea level rise were more a factor 
than changing water levels. A recent study (Jay, 2009) along the U.S Pacific Coast down into Mexico showed that tides have been increasing at a rate of $2.2 \%$ per century. In Astoria, Oregon, tides were increasing at the highest rate found for the study area, about $25 \mathrm{~cm}$ per century. The study concluded the effects of sea level rise on tidal amplification would result in greater rates of shore erosion. It is likely the impact on shore erosion will be most pronounced for mesotidal (2-4 m mean tidal range) and macrotidal ( $>4 \mathrm{~m}$ mean tidal range) coasts, where coarser sediment entrainment and transport by the tides already occurs.

One specific result of increasing tidal velocities could be greater scour of bridge and pier pilings. Most studies of scour around pilings have focused on unidirectional flow conditions typical of rivers (Richardson and Davis 2001), rather than bidirectional flow that occurs in tidal conditions. Some recent studies (e.g., Escarameia 1998; Vasquez and Walsh 2009) however have examined scour under tidal conditions, with respect to flood duration, the effect of reversal on flow direction, etc. A growing literature (Stevenson, et al. 1988) has documented that sinusoidal tides seldom characterize coastal areas, and more commonly tidal cycles display strong differences between time and peak velocities with respect to flood and ebb tides (termed time velocity asymmetry) according to Postma (1961). This phenomenon where peak velocities typify one part of the tidal cycle certainly can affect the nature of scour on the pilings. In many areas, especially estuarine channels, there is evidence that ebb domination eventually emerges over the cycle of channel development (Stevenson, et al 1988). How sea level rise will affect such channels, particularly as modified by shore protection features, has yet to receive close examination.

Ultimately, the major limitation in forecasting whether rising sea levels will amplify the tidal frame and increase tidal velocities and, in addition, whether existing or future shore protection features could contribute to this trend, is a lack of specific information of the relations of sea level rise to tidal dynamics for many developed coasts. This information includes temporal trends in sea level rise vis-à-vis changes in tidal amplitude, and adequate baseline data on port hydrography, beyond current velocities, where dredging and new construction may be enlarging or contracting the area flooded. The approaches to the Port of Baltimore, for example, are dredged often enough, the hydrographic characteristics could vary substantially from one year to the next. Such changes also affect wave characteristics.

\section{Developing a Regional Risk Profile}

\subsection{A Risk Methodology}

Probabilistic risk analysis as described by Ayyub (2003), Kumamoto and Henley (1996), and Modarres, et al. (1999) can be used to develop the overall risk analysis methodology suitable for quantifying and managing risks associated with sea-level rise. Risk assessment is a systematic process for quantifying and describing the nature, likelihood and magnitude of risk associated with some substance, situation, action or event, including consideration of relevant uncertainties (Ayyub 2003). Its objective is to provide, to the maximum extent practical, a scientific basis for answering the following questions (adapted after Kaplan and Garrick 1981):

- What could happen?

- How can it happen?

- How likely is it to happen?

- What are the consequences if it happens and associated uncertainties?

- What can be done to reduce the risks in a cost effective manner?

- What effects would these risk management decisions have on subsequent risks and options?

In an all-hazard context, risk analysis answers these questions by defining an exhaustive set of hazard or threat scenarios, assessing the likelihoods, vulnerabilities, and consequences reflecting existing threat or hazard reduction countermeasures, vulnerability reduction actions, and consequence mitigation actions. The combination of these three fundamental elements (hazard or threat, vulnerability, and consequence) gives the familiar expression for risk, $\mathrm{R}$, as provided in Eq. 1 .

The process of risk management entails identifying actions, including countermeasures, planning options, land-use changes, consequence mitigation strategies, etc. aimed at reducing or minimizing these risks in an

Published by Atlantis Press

Copyright: the authors 


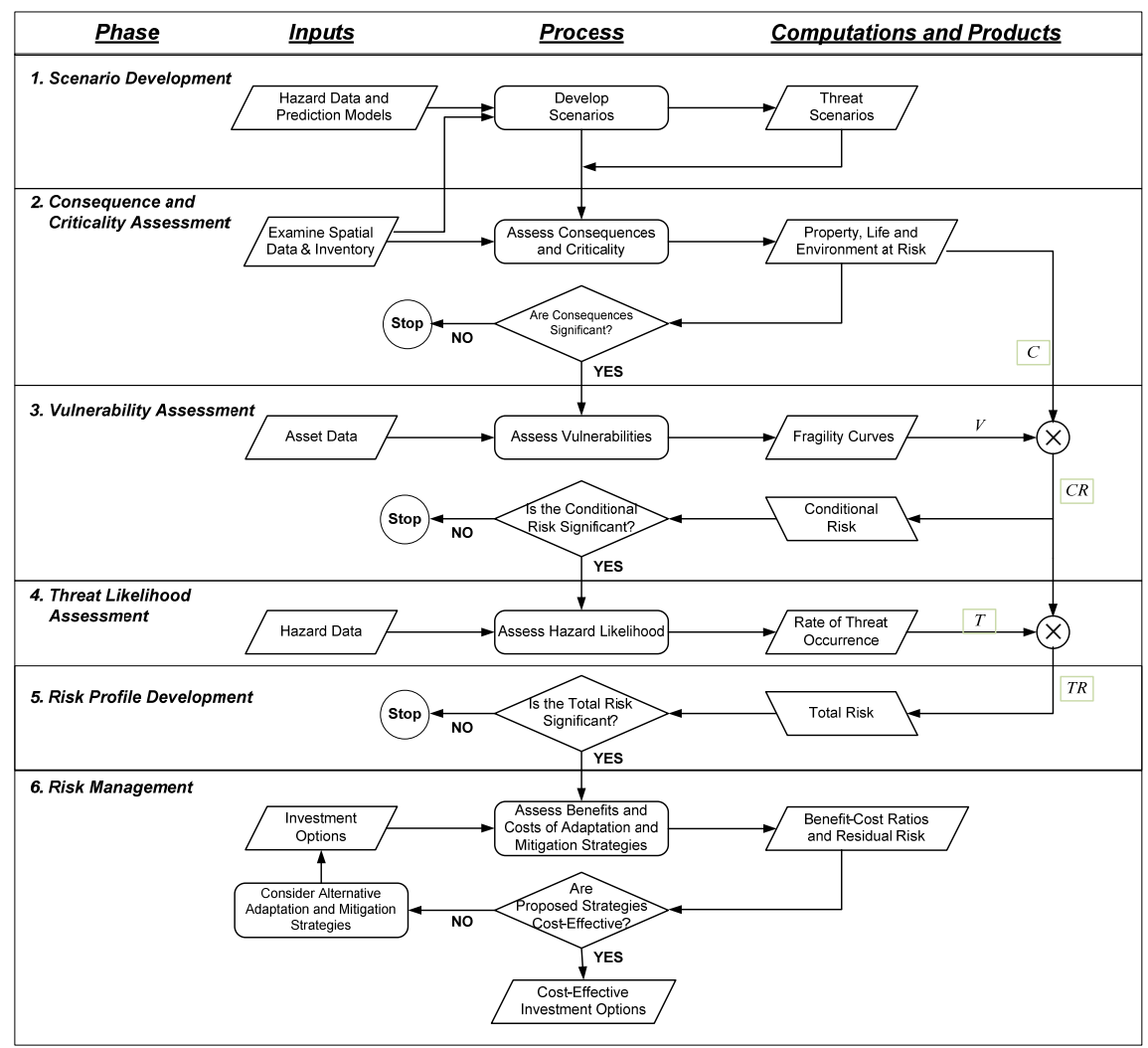

Fig. 1. The critical asset and portfolio risk analysis (CAPRA) methodology. and achieve all-hazard risk reduction objectives (Ayyub et al. 2007; McGill, et al. 2007).

Ayyub et al. (2007) developed an approach called the Critical Asset and Portfolio Risk Analysis (CAPRA) Methodology. In general, CAPRA is a fivephase process. CAPRA consists of several steps as shown in Figure 1 and discussed below:

- Scenario Identification: This step characterizes the functions (or missions) applicable to an asset, portfolio, and region and identifies hazard and threat scenarios that could cause significant regional losses should they occur. For natural hazards, this phase considers the

efficient and cost-effective manner with limited impact on future options. The selection of risk reduction alternatives depends on two factors - their cost to implement and relative cost-effectiveness. A common measure of cost-effectiveness for a given investment alternative is its benefit-to-cost ratio. In general, the computation of defensible benefit-to-cost ratios requires consideration of all aspects of risk, including consequence (economic loss, public health and safety, etc.), vulnerability (security and physical), and threat likelihood within a unified probabilistic framework. The rationale behind this assertion is that a probabilistic paradigm permits rational and coherent comparisons among decision alternatives that affect multiple assets to determine the most cost-effective risk reduction strategies. Furthermore, knowledge of the quantitative risks under various investment alternatives facilitates a rational comparison with other societal risks (such as fire, earthquake, disease, flood and other natural hazards) to assist in establishing acceptable risk levels estimated annual rate of occurrence, and screens out infrequent scenarios. The outcome of this phase is a complete set of hazard and threat scenarios that are relevant to the region under study.

- Hazard Likelihood Assessment: This step produces estimates of the annual rate of occurrence for each threat or hazard scenario including the time-variant hazard profile associated with sea-level rise for a region. For natural hazards, the results from this phase yield an annual rate or probability of occurrence for a hazard affecting the asset or a region and the intensity of the hazard as a function of time.

- Vulnerability Assessment: This step estimates the effectiveness of measures to protect, reduce hazard intensity, detect, delay, respond to, and eliminate a hazard that might cause harm to a region. This phase provides estimates of the probability of success for each hazard scenario, and, if combined with estimated losses, yields an estimate of conditional risk. 


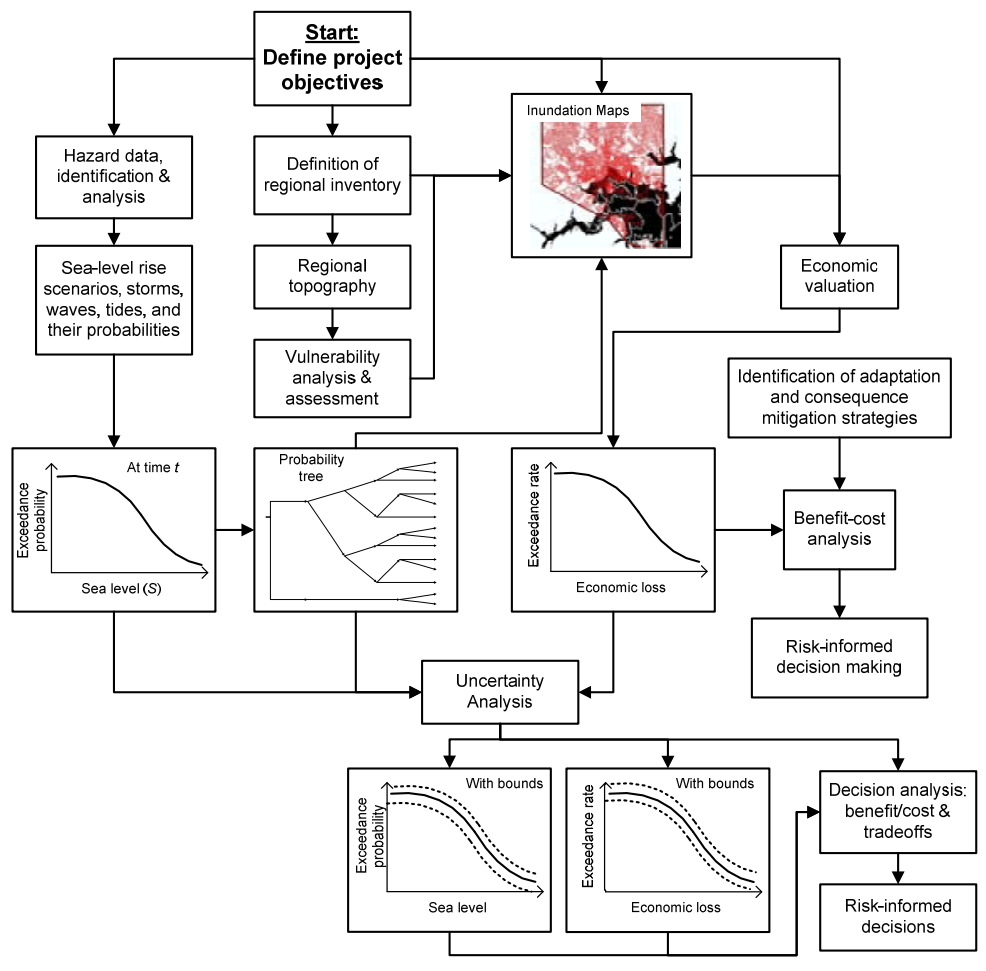

Fig. 2. A risk methodology for seal-level rise at a particular region. that is dependent on $S$ and $i$, scenarios of underlying variables $(j)$ defining $\lambda_{j}$, and respective probabilities $Q_{j}$, and the conditional probability $P(C>c)$ with which a consequence valuation $(C)$ exceeds different levels ( $c$ ) for $i, j$ and coastal state at time $t$. A loss-exceedance probability at time $t$ can be expressed as follows (Ayyub, et al 2011):

$P(C>c ; t)=\sum_{i} P_{i}\left(\int_{s} f_{S}\left(\sum_{j} \lambda_{i j} Q_{j} P(C>c \mid i, j)\right) d s\right)$

where $f_{S}$ is the probability density function of sea level $(S)$ at time $t ; P_{i}$ is the probability of a scenario of underlying variables $(i)$ defining $S ; \lambda$ is the regional storm rate that is dependent on $S$ and $i ; Q_{j}$ is the probability of a scenario of underlying variables $(j)$ defining $\lambda$; and $P(C>c \mid i, j)$ is the probability that the consequence $C$ exceeds $c$ under a state defined by the pair $(i, j)$ and the corresponding state of the coast at time $t$. Summations are over all scenario types $i$ and $j$ using a suitable discretization. The increased storm activities would include increased water depth, tidal effects, shoreline changes, if any, and wave run-up. This model is consistent with recently developed and used risk model for natural hazards, such as the risk models for developing protection strategies of hurricane-prone regions (Ayyub, et al. 2009a and 2009b, USACE 2006).

Figure 2 defines a logic and computational flow diagram for the proposed risk methodology for sea-level rise at a particular region starting with hazard identification and definition, followed by inventory definition to estimate losses based on inundation mapping, and finally constructing risk profiles and estimating associated uncertainty. Figure 3 provides the corresponding probability and risk tree based on the discretization of the underlying variables and system states according to Eq. 6 .

One of the objectives of the risk analysis is to quantitatively assess the uncertainties associated with 


\begin{tabular}{|c|c|c|c|c|c|c|c|c|c|}
\hline \multicolumn{2}{|c|}{$\begin{array}{c}\text { Regional hazard } \\
\text { analysis (sea-level rise } \\
\text { and probabilities) }\end{array}$} & \multicolumn{2}{|c|}{$\begin{array}{c}\text { Regional hazard } \\
\text { analysis (storms and } \\
\text { rates) }\end{array}$} & \multicolumn{3}{|c|}{$\begin{array}{l}\text { Vulnerabilities (conditional } \\
\text { inundation per event) }\end{array}$} & \multicolumn{2}{|c|}{$\begin{array}{l}\text { Consequence } \\
\text { severity } \\
\text { valuation }\end{array}$} & \multirow{2}{*}{\begin{tabular}{|c|} 
Risk profiles \\
Economic risk (\$)
\end{tabular}} \\
\hline \begin{tabular}{|c|}
$\begin{array}{c}\text { Scenarios } \\
\text { and } \\
\text { probabilities } \\
\left(P_{i}\right)\end{array}$ \\
\end{tabular} & $\begin{array}{c}\text { Sea-level at } \\
\text { time } t\end{array}$ & \begin{tabular}{|c|}
$\begin{array}{c}\text { Scenarios } \\
\text { and } \\
\text { probabilities } \\
\left(Q_{j}\right)\end{array}$ \\
\end{tabular} & Rate $\left(\lambda_{i j}\right)$ & \begin{tabular}{|c|}
$\begin{array}{c}\text { Regional } \\
\text { inventory } \\
\text { (GIS) }\end{array}$ \\
\end{tabular} & $\begin{array}{c}\text { Regional } \\
\text { topography }\end{array}$ & $\begin{array}{l}\text { Underground } \\
\text { water levels }\end{array}$ & $\begin{array}{l}\text { Assumed } \\
\text { measures }\end{array}$ & $\begin{array}{l}\text { Economic } \\
\text { loss }(\$)\end{array}$ & \\
\hline $\begin{array}{c}\left(\text { Scenario, }, p_{1}\right) \\
\left(\text { Scenario }, p_{2}\right) \\
\vdots \\
\left(\text { Scenario, } p_{1}\right) \\
\vdots \\
\left.\text { Scenario } 0_{N}, p_{N}\right)\end{array}$ & $\begin{array}{l}\text { Probability } \\
\text { distribution } \\
\text { of sea- } \\
\text { level } f_{S}\end{array}$ & $\begin{array}{c}\left(\text { Scenario }_{1}, q_{1}\right) \\
\left(\text { Scenario }{ }_{2}, q_{2}\right) \\
\vdots \\
\left(\text { Scenario }_{1}, q_{i}\right) \\
\vdots \\
\left(\text { Scenario }_{N}, q_{N}\right)\end{array}$ & \begin{tabular}{|l|} 
Storms \\
with \\
varying \\
intensities, \\
waves, \\
tides, and \\
associated \\
rates
\end{tabular} & $\begin{array}{l}\text { Property } \\
\text { Populatior } \\
\text { Environ. }\end{array}$ & $\begin{array}{l}\text { Inundation } \\
\text { maps } \\
\text { Impacted } \\
\text { property } \\
\text { Impacted } \\
\text { population } \\
\text { Impact on } \\
\text { environ. }\end{array}$ & $\begin{array}{l}\text { Fresh water } \\
\text { maps } \\
\text { Salinity levels } \\
\text { Impact on } \\
\text { water } \\
\text { resources }\end{array}$ & \begin{tabular}{|l|}
$\begin{array}{l}\text { Regional } \\
\text { planning \& } \\
\text { policies }\end{array}$ \\
Shoreline \\
protection \\
Asset \\
protection \\
Global
\end{tabular} & $\begin{array}{l}\text { Valuation } \\
\text { of land use } \\
\text { changes, } \\
\text { land loss, } \\
\text { property, } \\
\text { environ., } \\
\text { meeting } \\
\text { water } \\
\text { needs, etc. }\end{array}$ & $\begin{array}{l}\text { Loss exceedance } \\
\text { rates \& probabilities } \\
\text { as a function of time } \\
\text { Benefits of measure } \\
\text { Benefitcost analysis }\end{array}$ \\
\hline & & & Sample pro & & & & & & $\begin{array}{l}\text { Point estimates } \\
\text { with epistemic } \\
\text { uncertainty } \\
\text { estimates }\end{array}$ \\
\hline
\end{tabular}

Fig. 3. A probability and risk tree for seal-level rise at a particular region. sources of uncertainty are referred to as epistemic (knowledge-based) uncertainty. The distinction between what is aleatory and what is epistemic uncertainty can often seem arbitrary. For example, the distinction depends on the models that are used in a particular analysis. In addition, their estimates can change in time. Nonetheless, making a distinction between the sources of uncertainty in a logical manner helps ensure that all uncertainties are quantified and those that can be reduced with additional data or knowledge are identified. In principle, epistemic uncertainties are reducible with the collection of additional data or the use/development of improved models. However, in a given project, it is typically not possible to reduce these uncertainties. It should be noted that epistemic uncertainties in each part of the analysis lead to uncertainty in the final risk results. Propagating the uncertainties of the individual parts of the analysis through to the final result produces a probability distribution on the risk profile as provided in Figure 2.

\subsection{Hazard Analysis}

This section provides a preliminary demonstration of the proposed methodology using publically available information on the City of Baltimore (Ayyub et al. 2011). The first step is to estimate the sea level rise as a function of time. Data obtained from the National Oceanic and Atmospheric Administration (NOAA) website was used as lower bound on the estimates. The data includes current sea level-rise trends for the city of Baltimore recorded for over 100 years at Baltimore (NOAA station \# 8574680) and its record goes back to the year 1902. Figure 4 shows current sea level trends for Baltimore along with a trend line. This trend line is used to estimate future sea level elevations using a linear trend for the purpose of demonstration, and it is specific for the station location. The resulting linear trend is

$$
\text { Sea level }=0.0031 y-5.8699
$$

where $y$ is the year, such as 1992 . Using this model, the predictions of Table 1 can be obtained for 200 years. It should be noted that the results displayed in this table, are solely based on current sea level rise trends and do not include predictions made by the IPCC (2007) based 
on scenario A1B (see Figure 5) defining economic, energy and population trends, and not accounting for other effects reported in other studies, such as the melting of any ice masses (Vermeera and Rahmstorf 2009) where the following model was proposed:

$$
\frac{d H(t)}{d t}=a\left(T-T_{0}\right)+b \frac{d T}{d t}
$$

where $H=$ sea level as a function of time $t ; T=$ temperature above the baseline temperature $T_{0}$ at which sea level is in equilibrium with climate. The first term in this equation models the long-term trend, and the second term accounts for the short-term effect since some components of sea level adjust quickly to temperature changes, e.g., the heat content of the oceanic surface mixed layer. The temperature $T$ requires some time to achieve its full effect on the sea-level rise, called the time lag $\tau$, i.e., $T$ should be the temperature value at $\tau+t$. The model parameters $a, b, \tau$ and $T_{0}$ can be empirically estimated from data. Using A1B IPCC scenario with temperature range above 1980-2000 temperature of 2.3 to $4.3^{\circ} \mathrm{C}$, the sea-level rise above the 1990 level in the year 2100 is estimated to have an average of $124 \mathrm{~cm}$ and within the range 97 to $156 \mathrm{~cm}$; about 3 -orders of magnitude of the IPCC predictions.

Table 1. Sea level prediction for the City of Baltimore (for illustration purposes only).

\begin{tabular}{lll}
\hline Year & $\begin{array}{l}\text { Mean Sea } \\
\text { Level }(\mathrm{m})\end{array}$ & $\begin{array}{l}\text { Sea-level rise, } \mathrm{m} \\
(\mathrm{ft})\end{array}$ \\
\hline 2000 & 0.3301 & $0(0)$ \\
2010 & 0.3611 & $0.031(0.102)$ \\
2020 & 0.3921 & $0.062(0.203)$ \\
2030 & 0.4231 & $0.093(0.305)$ \\
2040 & 0.4541 & $0.124(0.407)$ \\
2050 & 0.4851 & $0.155(0.509)$ \\
2060 & 0.5161 & $0.186(0.610)$ \\
2070 & 0.5471 & $0.217(0.712)$ \\
2080 & 0.5781 & $0.248(0.814)$ \\
2090 & 0.6091 & $0.279(0.915)$ \\
2100 & 0.6401 & $0.310(1.017)$ \\
2110 & 0.6711 & $0.341(1.112)$ \\
2120 & 0.7021 & $0.372(1.220)$ \\
2130 & 0.7331 & $0.403(1.322)$ \\
2140 & 0.7641 & $0.434(1.424)$ \\
2150 & 0.7951 & $0.465(1.526)$ \\
2160 & 0.8261 & $0.496(1.627)$ \\
2170 & 0.8571 & $0.527(1.729)$ \\
2180 & 0.8881 & $0.558(1.831)$ \\
2190 & 0.9191 & $0.589(1.932)$ \\
2200 & 0.9501 & $0.620(2.034)$
\end{tabular}

\subsection{Land, Asset and Resource Inventory}

Much information is available in geographical information system (GIS) format about the City of Baltimore, thus it is used for demonstration purposes. In an effort to most efficiently and effectively analyze this information and how it can be potentially affected by sea-level rise, it is important to first indentify what type of information is needed to sufficiently capture the key assets to define the consequences of greatest concern. The key assets of concern identified in this case study include the following main categories (Ayyub et al. 2011):

1. People. Three methods were identified to estimate the population affected: one method uses the Census data, and the other two use Real Property data.

- 2000 Census Tract data and population counts for each tract - For each census that the United States performs every 10 years population counts are tallied and divided into small areas within each county called tracts. Free GIS data files are published for public use that include the size of the tract and the number of people. An approach of counting populations affected is by using this population data to compute population density based on census tracks and multiply the population density by the affected areas. Other approaches are offered below.

- Real Property "Dwelling Units" data - For each property listed in Baltimore City information on the number of dwelling units is available. Totaling all the affected dwelling units within the area of concern then multiplying this by an average number of people per household is another possible population count method.

- Real Property "Zoning Code" data - Each property also has a code associated with it that corresponds to its intended use (such as commercial, residential or industrial are the three main categories). For each residential zoning code, minimum and maximum numbers of units per acre allowed by City of Baltimore laws are provided. A third method of counting people affected is to estimate the number of dwellings based on the area of the property and the zoning code, then multiply this number by the estimated number of people per dwelling.

The first method is used for the case study of the City of Baltimore. The last two methods may be used; however, they involve uncertainty due to reliance on several assumptions. 


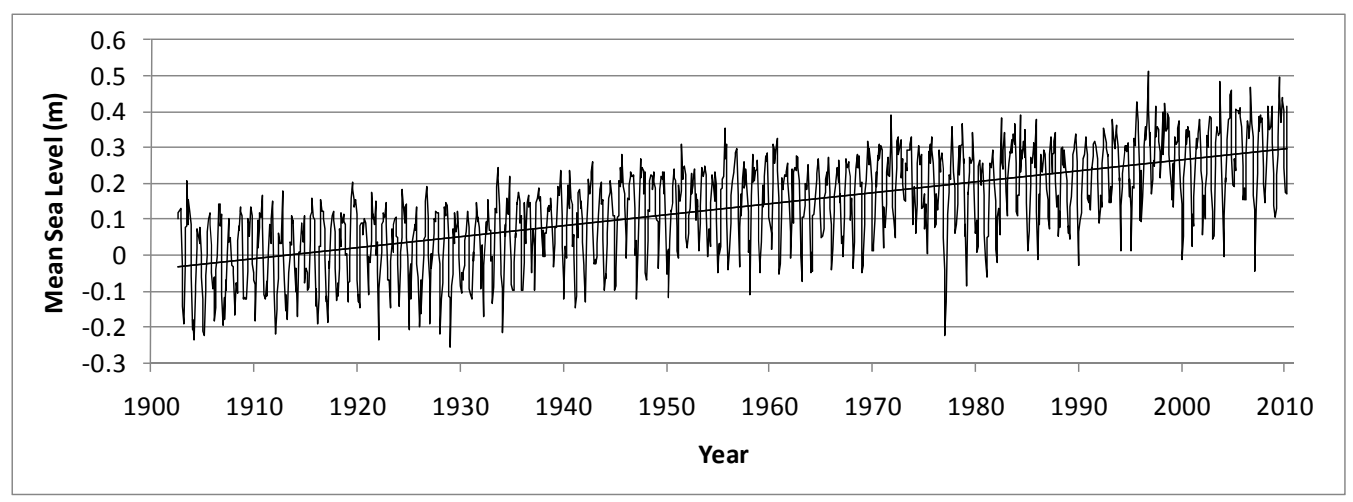

Fig. 4. Mean sea level trend for Baltimore, MD.

2. Land and Environment. Inundation of land and its impact on the environment is another primary loss component. By estimating areas of inundation and landuse types, environmental impacts can be assessed to facilitate a proper valuation.

3. Property. Of greatest importance herein is the property loss (using valuations in dollars) that could result from a sea-level rise. The Real Property dataset provides a wide variety of information about each property. Of greatest importance is the approximate cost of the property in dollars. While this may not perfectly represent the cost of the buildings on the property it has a strong enough correlation to make the assumption that high property values typically indicate that the building(s) located on that property also have higher value and thus high cost of replacement if damaged. In addition, values for the approximate square footage can be obtained that can be used with valuation unit prices to estimate replacement and content values. Using zoning classification would offer the means to estimate residential, commercial, industrial, and other property values.

$\underline{4 .}$ Roadways and Railways. The length of roadways and railways within inundation areas can be estimated with respective daily traffic volumes and movement of goods. The City of Baltimore provided many files including all roads (small alleyways to large highways), and railways. These two variables would offer strong bases for valuation.
5. Other Specific Assets. There are many other buildings and other structures throughout the City along the coastal lines, many of which would be of particular importance to know about for consequence estimation, such as:

- Ports and shipyards

- Manufacturing plants

- Water intakes

- Government structures

- Stadiums

- Religious institutions

- Commercial and retail structures

- Historical and cultural landmarks

- Government structures

- Schools

- Assisted living, nursing homes

- Hotels

The properties of each of these specific assets include the relevant information that would enable consequence estimation including the approximate number of people that could be affected.

\subsection{Inundation Mapping and Risk Profile}

Assuming that the City of Baltimore does not have a coastal protection system in place, and therefore is vulnerable to sea-level rise, the development of inundation maps requires topographical maps for the City of Baltimore. The sea-level rise trends of Table 1 were used in combination with the topographical data to define the inundated areas. Using an inventory summary of affected land, assets and resources with hypothetical valuations, and loss intensity, i.e., a risk profile, can be produced as provided by Ayyub et al. (2011). Figure 6 shows the trends of the inventory components affected by inundation. 


\section{Developing a Regional Risk Profile}

The risk management phase assesses the costeffectiveness of proposed countermeasures and consequence mitigation strategies for reducing the risk associated with an asset or portfolio of assets or a region. In the context of sea-level rise, countermeasures aim to reduce vulnerabilities of coastal lines, property and asset exposure, impact on resources and populations, and land use changes. Consequence mitigation strategies aim to reduce the potential consequences given the occurrence of a successful scenario. Risk management entails decision analysis for a cost-effective reduction of risk given finite available resources. The benefit of a risk mitigation action can be assessed as the difference between the risk before and after implementation (Ayyub 2003):

$$
\text { Benefit }=\text { unmitigated risk }- \text { mitigated risk }
$$

The benefit-to-cost ratio can be calculated as:

$$
\text { Benefit-to-Cost Ratio }(\mathrm{B} / \mathrm{C})=\text { Benefit/Cost }(10)
$$

where ratios greater than one are desirable. The cost in Eq. 10 is the cost to implement and sustain the risk mitigation action. In general, larger benefit-to-cost ratios indicate better risk mitigation actions from a costeffectiveness standpoint. However, selection of the optimal risk mitigation action must also consider the cost to implement relative to available resources as well as whether the strategy achieves risk reduction objectives.

The probability that a favorable benefit-to-cost ratio will be realized can be represented as:

$$
P\left(\frac{\text { Benefit }}{\text { Cost }} \geq 1\right)=1-P(\text { Benefit }- \text { Cost } \leq 0)
$$

The model in Eq. 9 is analogous to the familiar stressstrength model used in reliability engineering (Ayyub 2003, Modarres, et al. 1999). In general, both benefit and cost in Eq. 5 are random variables that can assume any parametric distribution. With knowledge of these distributions, the probability of realizing a favorable benefit-to-cost ratio can be computed using techniques

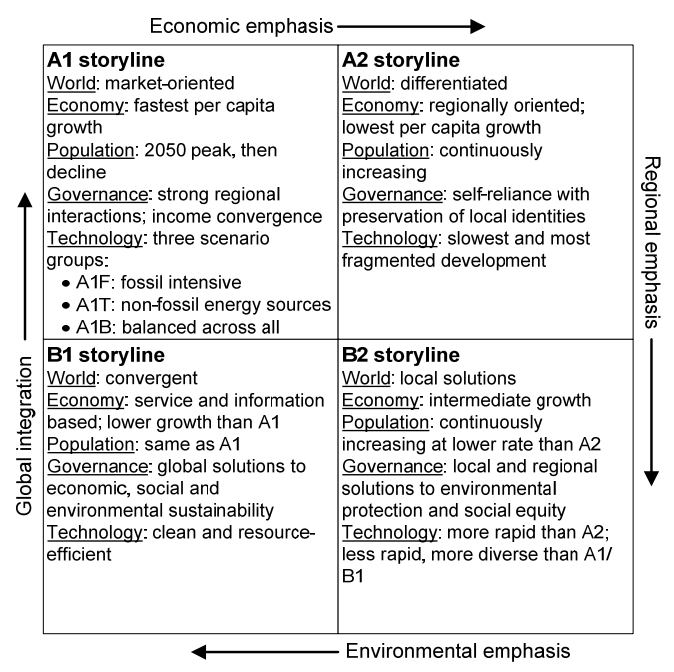

Fig. 5. The IPCC storylines, i.e., scenarios (Adapted from IPCC 2007).

such as the second order reliability model (Ayyub 2003).

\section{Natural or Soft Engineering Solutions to Sea Level Rise}

The use of natural systems for mitigation of coastal erosion, flooding hazards, and the overall coastal vulnerability to accelerate sea level rise is gaining in popularity. The most often cited natural solutions to moderating the extent and power of storm surges during hurricanes are coastal wetlands, particularly marshes. The general rule of thumb is that surge height will be decreased for each linear $2.5 \mathrm{~km}$ of marshes, which unfortunately lacks rigorous testing. It was hoped during Hurricane Katrina, whose track transverse a considerable distance of coastal marshes along the Louisiana coast, that the storm surge would have been appreciably diminished, though there have been no concrete data yet produced that has determined definitively the degree of surge dampening that could be attributed to the marshes. In the event, whatever dampening of surge elevations the marshes caused, the track of the storm flooded New Orleans after it moved to the northwest of the city. 


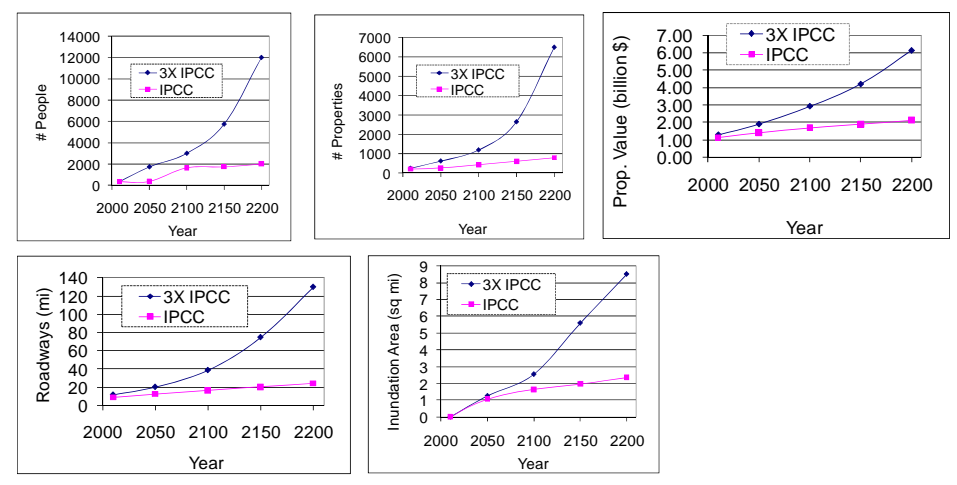

Fig. 6. Illustrative inundation inventory components necessary for quantifying risk profiles for the City of Baltimore.

Several problems make assessing the possible degree of coastal flood protection that might afforded by marshes and other coastal wetlands (like swamps) problematical. Marsh canopies differ in height and structure, biomass, and the extent of coverage of intact marshes themselves can vary widely, especially in an area of active marsh loss (e.g., Louisiana). An additional complication occurs when winds from a storm (i.e., hurricane) where wind fields can affect coasts long before the arrival of the storm surge. Resio and Westerink (2008) theorize that in these circumstances sustained winds from exceptionally strong hurricanes can blow down grasses and other marsh plants (known as lodging), effectively negating the ability of marshes to dampen surge levels. Some evidence suggests that this is indeed what happened during Hurricane Katrina (Resio and Westerink 2008).

Some recent findings link excess anthropogenic nutrient inputs in marshes along the U.S. Atlantic and Gulf Coasts to organic matter decomposition and root degradation (Swarzenski et al. 2008). Thus, poor and shallow rooting as well as the lack of structural strength of the root mat can greatly increase the likelihood of plant lodging in marshes with even low intensity hurricanes (Category 1 or 2). In fact, the general appearance of such marshes can be deceptive with regard to their potential for storm surge and wave dampening. Turner et al. (2004) found a strong bias to lush above-ground biomass while the rooting is poorly developed with low shear strength.

It should not be construed, however, that natural solutions have no real contribution to make in planning for coastal protection in an era of rapid sea level rise. Rather the appropriate conclusion is that wetlands in particular clearly enhance coastal sustainability especially with regard to ecosystem services; nevertheless, their role in coastal protection is likely to be secondary to more traditional structural measures. Moreover, with rates of loss of coastal marshes likely to increase dramatically with accelerated sea level rise, marsh survival is its own unique problem.

\section{Concluding Remarks and Research Needs}

Quantifying risk using a probabilistic framework produces hazard (elevation) and loss-exceedance probability curves based on a spectrum of sea-level rise scenarios according the mean sea level as a function of time and increased storm rates with associated surges, waves and precipitation with uncertainty quantification. The methodology provides a process for evaluating the loss potential for a region covering land-use changes, population affected, and property at risk by considering the topography and asset inventory for the region. The quantification of risk will enable decision makers to consider various alternatives to manage risk through setting appropriate policy relating to land use, land-use changes, infrastructure planning, building requirements and permits, water resource planning, and the enhancement of consequence mitigation measures.

This preliminary, conceptual framework for quantifying risks associated with sea-level rise requires refinement and development of computational details. Moreover the state of the inventory requires further developing by focusing on the coastal areas. The inventory used in this paper is developed for rail safety studies and is incomplete and/or inaccurate along the coastal lines. The increase in storm activity with wave run-up intensity escalation due to the rising sea level requires further investigation. The impacts of such increased activities at coastal lines would lead to interdependence with land-use and human-activity changes. 
Models for global sea level rise in the Fourth Assessment of IPCC indicate that a dramatic rise in the sea level trend is only a few decades away. The threat posed by this rise to the world's coastal infrastructure is probably without historical parallel; nevertheless, meeting it will require that science and engineering provide the necessary information on future coastal dynamics and risk that will affect structures and the social - economic and life - sustaining services they provide. Fulfilling this mandate will not be easy, as the science for future sea level change is still not settled and the requisite data for developing engineering solutions even for specific localities are incomplete or absent. However, none of this will forestall calls for the engineering community to provide a "fix" regardless of the lack of precedent or inadequate understanding.

One emerging consensus about future sea level rise is that, whatever its eventual magnitude (ignoring the calamity of an extensive polar melt down), rapid change (acceleration) is only decades away (IPCC 2007). Mobilizing the resources to address the vulnerability of existing coastal infrastructure and what may be done to lessen it (retrofitting, replacement or even redevelopment) is thus timely. For the assessments of structural capability of essential infrastructure to even overall risk to port operations from sea level rise, basic coastal science and engineering information on the following would seem a minimal requirement:

- Future shoreline position

- Storm wave height from evaluation of freeboard

- Wave power

- Changes in tidal hydrography

Determinations of all these essential factors in considering future sea level rise poses challenges; however it is possible to develop scenarios, if not exactly robust estimates, whereby planning can occur.

\section{Acknowledgements}

The authors acknowledge the financial support of the following units of the University of Maryland at College Park: College of Computer, Mathematical and Physical Sciences, A. James Clark School of Engineering, College of College of Behavioral and Social Sciences, Department of Geography, Department of Civil \& Environmental Engineering, and Center for Technology \& Systems Management, and the Council on Disaster Risk Management of the American Society of Civil
Engineers. Also, they acknowledge the assistance of CY. Chang, P. Broqueres, K. Markham, J. Ramirez, and A. Ritter.

\section{References}

1. Ayyub, B. M. 2003. Risk Analysis in Engineering and Economics, Chapman \& Hall/CRC Press, FL.

2. Ayyub, B. M., and Klir, G. J., 2006. Uncertainty Modeling and Analysis in Engineering and the Sciences, Chapman \& Hall/CRC, Press Boca Raton, FL.

3. Ayyub, B. M., Foster, J., McGill, W. L., 2009a. Risk Analysis of a Protected Hurricane-Prone Region I: Model Development, ASCE Natural Hazards Review, 10:2(38), 38-53.

4. Ayyub, B. M., McGill, W. L., Foster, J., Jones, H. W., 2009b, Risk Analysis of a Protected Hurricane-Prone Region II: Computations and Illustrations, ASCE Natural Hazards Review, 10:2(38), 54-67.

5. Ayyub, B. M., McGill, W. L., Kaminskiy, M., 2007, Critical Asset and Portfolio Risk Analysis for Homeland Security: An All-Hazards Framework, Risk Analysis Journal, 27(3), 789-801.

6. Ayyub, B. M., Ramirez, J., Markham, K., and Broqueres, P., 2011 (in press), Quantifying Regional Risk Profiles Attributable to Sea-Level Rise, ASCE Monograph, Reston, VA

7. Bruun, P. 1954. Coast erosion and the development of beach profiles. Beach erosion board technical memorandum. No. 44. U.S. Army Engineer Waterways Experiment Station, Vicksburg, MS.

8. Bruun, P., 1962. Sea level rise as cause of shore erosion. American Society of Civil Engineering Proceedings, Journal Waterways Harbors Division 88: 117-130.

9. CCSP, 2009. Coastal Sensitivity to Sea-Level Rise: A Focus on the Mid-Atlantic Region. A report by the U.S. Climate Change Science Program and the Subcommittee on Global Change Research, U.S. Environmental Protection Agency, Washington, DC.

10. Dean, R. G. 1977. Equilibrium beach profiles - U.S. Atlantic and Gulf Coasts. Ocean Engineering Report No. 12, University of Delaware, Newark, pp. 1-45.

11. Dean, R. G., 2002. Closure depth considerations along the Florida shoreline. UFL/COEL - 2002/009, Department of Civil and Coastal Engineering, University of Florida, Gainesville, Florida.

12. Escarameia, M., 1998. Laboratory investigation of scour around large structures in tidal waters. Conference on Basics of Sediment Transport and Scouring. HR Wallingford (http://kfki.baw.de/conferences/ICHE/1998Cottbus/55.pdf).

13. Fairbridge, R. W., 1950. The Geology and Geomorphology of Point Peron, Western Australia, J. of the Royal Society of Western Australia, 33, 1-43.

14. Fairbridge, R. W., 1958. Dating the Latest Movements in the Quaternary Sea Level. New York Academy of science Transactions, 20 471-482. 
15. Fairbridge, R. W., 1960. The Changing Level of the Sea, Scientific American, 202 (5), 70-79.

16. Fairbridge, R. W., 1961. Eustatic Changes in Sea-Level, in L. H. Ahrens, K. Rankama, F. Press and S. K. Runcorn (eds), Physics and Chemistry of the Earth, Vol. 4, London: Pergamon Press, 99-185.

17. Finkl, C W., Jr., (ed.), 2005. The Sun, Earth and Moon In Honor of Rhodes W. Fairbridge. J. of Coastal Research, Special Issue No. 42.

18. Finkl, C. W., Jr., (ed.), 1995. Holocene Cycles: Climate, Sea Levels, and Sedimentation. A Jubilee Volume in Celebration of the 80th Birthday of Rhodes W. Fairbridge. J. of Coastal Research, Special Issue No. 17.

19. Goda, Y., and Kudaka, M., 2007, "On the role of spectral width and shape parameters in control of individual wave height distribution," Coastal Engineering J., 49(3), 311335.

20. IPCC, 2007. Climate Change 2007: Synthesis Report. Contribution of Working Groups I, II and III to the Fourth Assessment Report of the Intergovernmental Panel on Climate Change, Geneva, Switzerland.

21. Jay, D. 2009. Evolution of tidal amplitude in the eastern Pacific Ocean. Geophysical Research Letters 36: L066041, doi: 10.1029/2008GL/036796.

22. Kaplan, S., and Garrick, J. B., 1981, "On the quantitative definition of risk," Risk Analysis Journal, 1(1), 11-27.

23. Kearney, M. S. 2008. The potential for significant impacts on Chesapeake Bay: Sea Level Impacts and Ecology. In M. McCracken (ed.), The Likelihood and Character of Large and Disruptive Climate Change. London: EarthScan, 85-100.

24. Komar, P. 1998. Beach Processes and Sedimentation. Second Edition. Prentice Hall, NJ.

25. Kumamoto, H., and Henley, E.J., 1996, Probabilistic Risk Assessment and Management for Engineers and Scientists, Second Edition, IEEE Press, New York.

26. Mackey, R., 2007. Rhodes Fairbridge and the Idea that the solar System Regulates the Earth's Climate, J. of Coastal Research, Special Issue No. 50.

27. McGill, W. L., Ayyub, B. M., Kaminskiy, M., 2007, A Quantitative Asset-Level Risk Assessment and Management Framework for Critical Asset Protection, Risk Analysis International Journal, Society for Risk Analysis, 27(5), 2007.

28. Modarres, M., Kaminskiy, M., and Krivstov, V., 1999. Reliability Engineering and Risk Analysis: A Practical Guide, Marcel Decker Inc., New York, NY.

29. NOAA. 1999. Assessment of the National Ocean Service's tidal current program. NOAA Technical Report NOS CO-OP 022. U.S Department of Commerce, Silver Spring, Md.

30. Postma, H. 1961. Suspended matter and secchi disk visibility in coastal waters. Netherlands Journal of Sea Research 1: 359-390.

31. Resio, D.T., and Westerink, J.J., 2008. Modeling of storm surges. Physics Today 61: 33-39.
32. Richardson, E. and Davis, S.. 2001. Evaluating scour at bridges: fourth edition. National Highway Institute, Federal Highway Administration, Hydraulic Engineering Circular No. 18.

33. Rosen, P., 1978. A regional test of the Bruun Rule on shoreline erosion. Marine Geology 26: M7-M16.

34. Ruggiero, P., Komar, P. D., and Allen, J. C., 2010. Increasing wave height and extreme value predictions: The wave climate of the Pacific Northwest. Coastal Engineering 57: 539-552.

35. Stevenson, J.C., Ward, L.G., and Kearney, M.S., 1988. Sediment transport and trapping in marsh systems: implications of tidal flux studies. Marine Geology 80: 37-59.

36. Swarzenski, C.M., Doyle, T.W., Fry, B., and Hargis, T. G., 2008, "Biogeochemical response of organic-rich freshwater marshes in the Louisiana delta plain to chronic river water influx. Biogeochemistry 90: 49-63.

37. Turner, R. E., Swenson, E. M., Milanj, C. S., Lee, M., and Oswald, T. A., 2004. Belowground biomass in healthy and impaired salt marshes. Ecological Research 19: 29-35.

38. USACE, 2006. Interagency Performance Evaluation Task Force Draft Report on "Performance Evaluation of the New Orleans and Southeast Louisiana Hurricane Protection System," Draft Volume VIII - Engineering and Operational Risk and Reliability Analysis, USACE, Washington, DC. https://IPET.wes.army.mil

39. Vasquez, J. A. and Walsh, B. W., 2009. CFD simulation of local scour in complex piers under tidal flow. Proceedings of the 33rd IAHR Congress: Water Engineering for a Sustainable Environment, International Association of Hydraulic Engineering \& Research (IAHR), pp. 913-920.

40. Vermeera, M., and Rahmstorf, S., 2009, Global sea level linked to global temperature, www.pnas.org/ cgi/doi/10.1073/pnas.

41. Zhang, K., Douglas, B.C., and Leatherman, S.P., 2004. Global warming and long-term sandy beach erosion. Climatic Change 64, 41-58. 